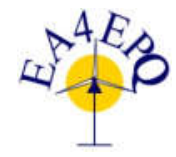

International Conference on Renewable Energies and Power Quality (ICREPQ'16)

Madrid (Spain), $4^{\text {th }}$ to $6^{\text {th }}$ May, 2016

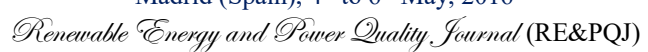

ISSN 2172-038 X, No.14 May 2016

\title{
Application of Biogeography Based Optimization Algorithm in Voltage Profile Improvement of Distribution Network by using DSTATCOM Considering Cable Aging Constraint
}

\author{
Seyed-Alireza Ahmadi ${ }^{1}$, Hossein Karami ${ }^{2}$, Vahid Vahidinasab ${ }^{1}$, Gevork B. Gharehpetian ${ }^{2}$ \\ ${ }^{1}$ Dept. of Electrical Engineering \\ Shahid Beheshti University \\ Tehran, Iran \\ Emails: se.ahmadi@mail.sbu.ac.ir, v_vahidinasab@,sbu.ac.ir \\ ${ }^{2}$ Dept. of Electrical Engineering \\ Amirkabir University of Technology \\ Tehran, Iran \\ Emails: h.karami@aut.ac.ir, grptian@aut.ac.ir
}

\begin{abstract}
In this paper, Biogeography Based Optimization (BBO) algorithm is used to improve voltage profile of the distribution networks considering cable aging constraint and optimal siting and sizing of DSTATCOMs. Recently, researchers show the importance of cable aging effects in the planning of power systems. Cable aging mostly happens due to metallic structure of power equipment such as cable sheathing erosion. Decreasing reliability of the system and higher risk of failure are some results of cable aging. In order to overcome this issue in power system, one of the best methods is the reduction of cable current flow by installing Flexible Alternating Current Transmission System (FACTS) devices. FACTS devices can help to overcome the hazards that happen in the operation stage of power systems. In this regard, Distributed Static Compensator (DSTATCOM) is used here. The IEEE 33-bus standard network is used in our experimental studies as the test system and load flow calculations are carried out by Backward/Forward sweep method in this work. Three scenarios are investigated in the simulation and the $\mathrm{BBO}$ algorithm is used to find optimal sites and sizes for each scenario. The results obtained from $\mathrm{BBO}$, show the privilege of the proposed method.
\end{abstract}

\section{Keywords}

Distribution networks, cable aging, voltage profile, DSTATCOM, optimal siting and sizing, Biogeography Based Optimization (BBO).

\section{Introduction}

Lifecycle management of equipments attracts a lot of attention in the area of power systems reliability assessment. Equipment aging increases the failure rate of a system and causes unplanned outage of power system. Cable aging as a common type of equipment aging, which happens due to metal structure erosion or weakening in insulation, should be decreased by both technical and maintenance ways. As the maintenance activities for prolonging equipment lifetime is expensive, decision makers in the industry prefer to overcome aging problem by technical ways and not to use maintenance activities as far as possible. Similar to this manuscript, many papers propose attractive technical solutions to mitigate cable aging problem [1-6]. In [4-5], cable aging constraint has been considered in the problem of Distributed Generations (DGs) placement. In [6], optimal placement and sizing of shunt compensators have been performed considering load variations and cable aging constraint. However, in the mentioned studies, voltage profile has not been investigated. In [3], voltage profile improvement considering cable aging has been studied by optimal placement of Distributed Static Compensator (DSTATCOM). However, the optimal size of DSTATCOM has not been investigated in [3]. In this paper, simultaneous consideration of cable aging and voltage profile is investigated, by optimal siting and sizing of DSTATCOMs. Many optimization algorithms have been introduced and applied in the engineering problems [7-12]. In this paper, Biogeography Based Optimization (BBO) algorithm [13] is used to find the optimal sites and sizes of DSTATCOMs to improve voltage profile in the distribution network, considering cable aging issues. The proposed method has been applied on IEEE 33-bus test system and suitability of $\mathrm{BBO}$ for this problem is shown in the results. In the next Section, the objectives of the paper are formulated and in 
Section III, a brief description about the DSTATCOM in load flow is provided. BBO algorithm is expressed in Section IV and simulation results of $\mathrm{BBO}$ algorithm for the problem is discussed in Section $\mathrm{V}$. finally the paper is concluded in section VI.

\section{Problem Statement}

One of the main hazards that reliability engineers are dealing with in the electric power industry is equipment failure. Cable aging which is a category of equipment aging increases the outage rate of lines in power system. In order to postpone these failures, the maintenance activities are suggested. Fig. 1 shows the popular bathtub curve. From this figure, it can be observed that by using preventive maintenance activities, the useful lifetime of an equipment such as cables can be increased. Despite all of the advantages that maintenance activities have regular maintenance costs a lot and needs expert engineers, so, it is not interested in the industry. As shown in Fig. 1, the process of cable aging can be reduced by suitable maintenance activities. However, this fact cannot be fully stopped. Previously, researchers demonstrate that by reducing the ratio of current flow to the nominal current, a longer lifetime for cables can be expected in the power system. In [5-6], minimization of the following equation proposed to reduce cable aging effect in power networks:

$\sum_{i=1}^{N_{\text {branch }}} \frac{\text { Nominal life of cable } i}{\text { Prolonged life of cable } i \text { after compensation }}$

By considering the voltage profile of the system in the objective function (OF), the $\mathrm{OF}$ can be summarized as follows:

$$
\begin{aligned}
O F= & \sum_{i=1}^{N_{\text {brongh }}} \frac{\text { Nominal life of cable } i}{\text { Prolonged life of cable } i \text { after compensation }} \\
& +\sum_{i=1}^{N_{\text {bus }}}|| V|-1|
\end{aligned}
$$

Both terms of the $\mathrm{OF}$ are in p.u. and so we sum them as shown in (2).

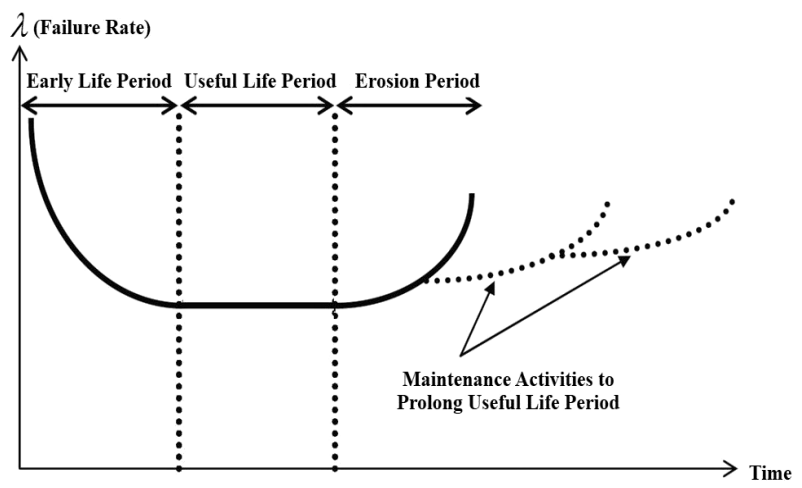

Fig. 1. Bathtub curve; prolonging lifetime of an equipment by using preventative maintenance

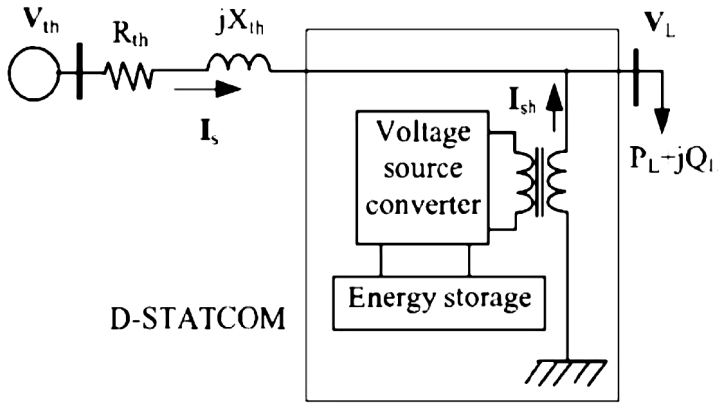

Fig. 2. A typical DSTATCOM diagram.

\section{DSTATCOM in Load Flow}

DSTATCOM by simultaneous injection and absorption of active and reactive current to the point of common coupling (PCC) connection can lead to proper control of reactive power in the distribution system. The steady state situation of this device, can help to reduce loss of the system and regulate voltage profile. Constant DC voltage is generated in DSTATCOM by using a DC voltage source and it is converted to $\mathrm{AC}$ voltage by a voltage source converter (VSC). DSTATCOM is usually connected to the distribution system via a coupling transformer [16]. The DSTATCOM can control power factor and voltage of its bus by setting proper magnitude and phase angle of output current as shown in Fig. 2. Injection or absorption of its current is indicated according to the bus voltage and strategy control of switching.

In this paper, DSTATCOM can only exchange reactive power and similar to many previous works, active power is neglected [17-19]. The model of steady state of DSTATCOM, which is used in this paper, is described in [20]. It should be noted that we use Backward/Forward sweep calculations to perform load flow in this paper.

\section{Biogeography Based Optimization Algorithm}

$\mathrm{BBO}$ is a novel optimization algorithm proposed by Dan Simon in 2008 [13] This algorithm looks at biogeography for its inspiration source. Animals and plants species in a neighboring islands group will migrate over ages between the islands for different reasons. Suitability of environmental specifications in some islands for species may lead to gather more species than other islands which have fewer species. The suitability of environmental specifications to absorb species can be quantified by assigning an island suitability index (ISI) to each island. Many specifications of the island may effect on ISI value. After assigning value to each specification, we have the ISI as a function of these values. Each value can be signified by a suitability index variable (SIV). The following formula can show a summary of the mentioned procedure:

Island $\rightarrow\left(\operatorname{spec}_{1}, \ldots\right.$, spec $\left._{n}\right) \rightarrow\left(S I V_{1}, \ldots, S I V_{n}\right) \rightarrow I S I$

Large ISI for an island represents abundance of species. These species can emigrate to other islands and so, the rate 
of emigration $(\mu)$ and the immigration rate of an island $(\lambda)$ is large and small, respectively. It is assumed that ISI and emigration (or immigration) rate has linear relation and are same for all population as shown in Fig. 3 .

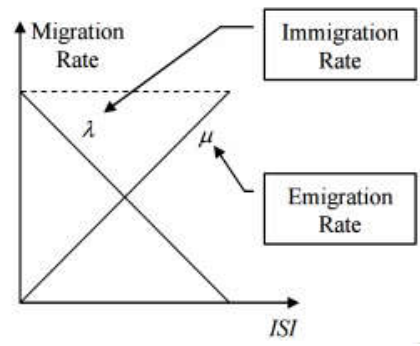

Fig. 3: ISI and island migration rate

A possible solution of a problem can be analyzed as the $n$-tuple $\left(\mathrm{SVI}_{1}, \mathrm{SVI}_{2}, \ldots, \mathrm{SVI}_{\mathrm{n}}\right)$ companion with the specifications of an island. An island ISI value can be considered as $\mathrm{OF}$ value joined with that solution. Determination of the solution as the aim of BOO algorithm can be achieved by maximizing of the ISI over the entire search space. The solution migration rates can be used to share specifications among islands. The decision of immigration of each island specification (SIV) is probabilistically set. Emigrating island is probabilistically chosen using roulette wheel selection normalized by $\mu$, If we decide to immigrate for a SIV. Then, the mutation is probabilistically performed to improve population diversity. A detail formulation of this algorithm is described in [13].

\section{Simulation Results}

In this paper, the IEEE 33-bus network is used for simulation (see Fig. 10). Data of this test system are reported in Appendix 1.

Three different scenarios are investigated here:

Scenario1: siting and sizing for one DSTATCOM:

In the first scenario of the studies, site and size of one DSTATCOM is investigated. The BBO algorithm is run for 500 iterations and the average and minimum values for the $\mathrm{OF}$ are shown in Fig. 4. The BBO algorithm, places the DSTATCOM on bus 17 with the size of $158.17 \mathrm{kVA}$. As shown in Fig. 4, it can be concluded that the convergence of $\mathrm{BBO}$ algorithm is suitable for solving this problem and finding global optimum value. Voltage profile of the system is improved considering cable aging constraint as depicted in Fig. 5. In this paper, the readers can compare the situation of system voltage profile with and without DSTATCOM.

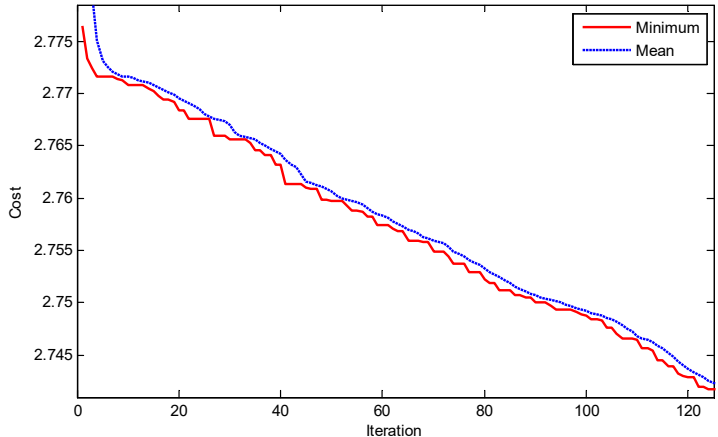

Fig 4. Mean and minimum values of the objective function for each iteration in scenario 1

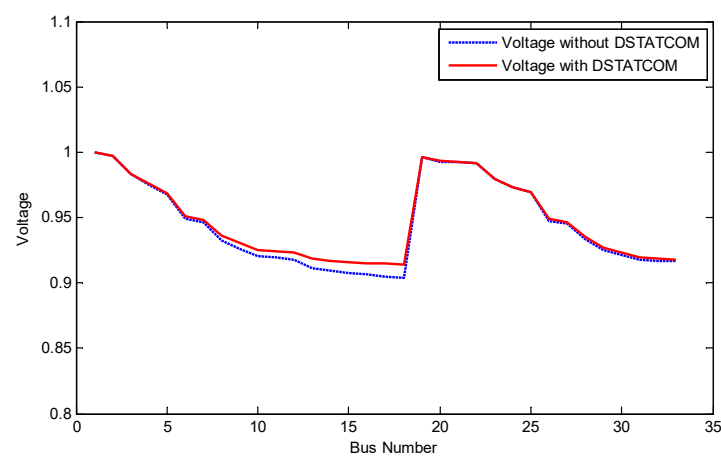

Fig 5. Voltage profiles with or without DSTATCOM in scenario 1

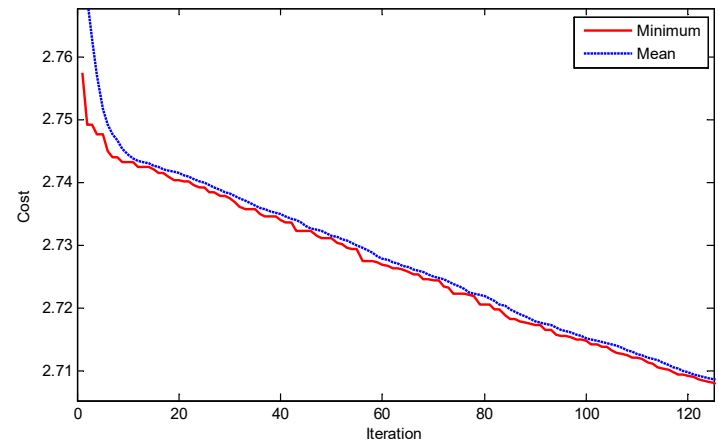

Fig 6. Mean and minimum values of the objective function for each iteration in scenario 2

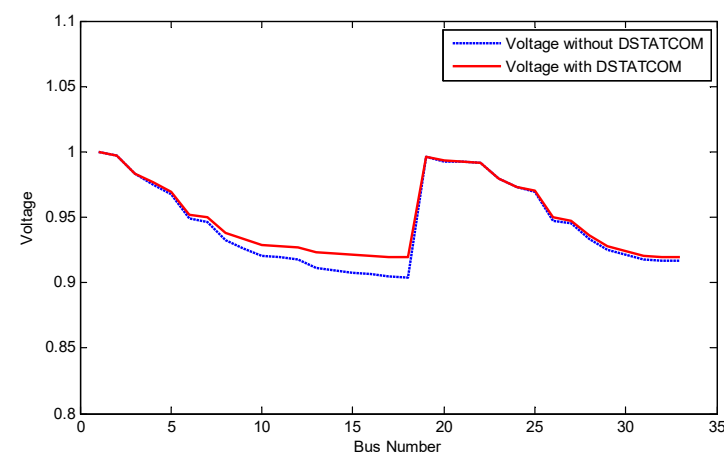

Fig 7. Voltage profiles with or without DSTATCOM in scenario 2 


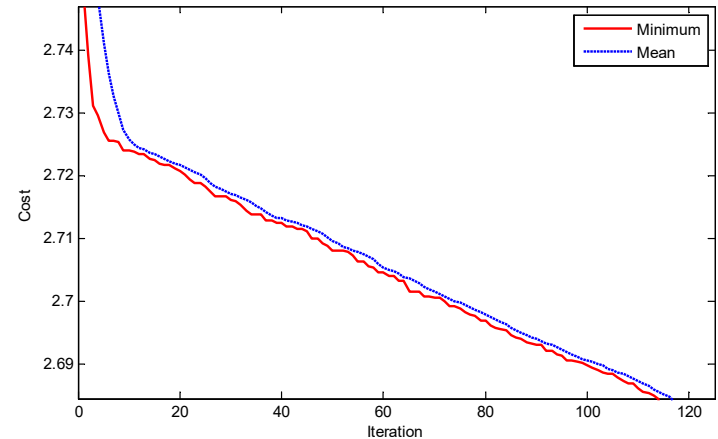

Fig 8. Mean and minimum values of the objective function for each iteration in scenario 3

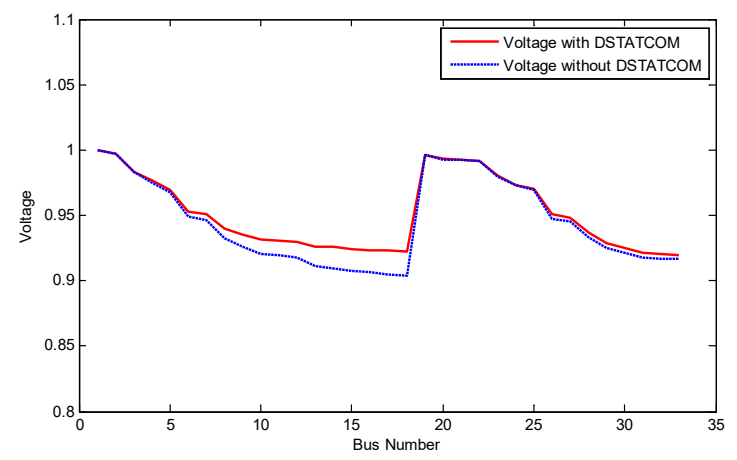

Fig 9. Voltage profiles with or without DSTATCOM in scenario 3

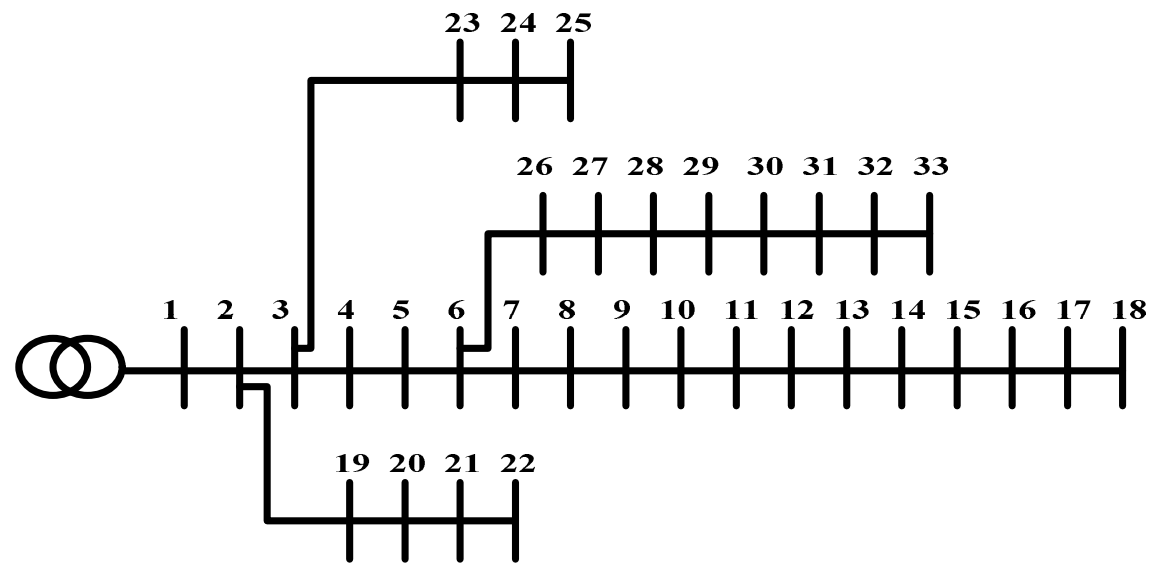

Fig. 10. IEEE 33-Bus test system

a) Scenario2: optimal sites and sizes of two DSTATCOMs:

In the second scenario, siting two DSTATCOMs are studied and optimal sites and sizes of them are found during the optimization process which is done by BBO. The result of 500 iterations of BBO algorithm, places the DSTATCOMs on bus 17 and 14 with the sizes of $138 \mathrm{kVA}$ and $129.76 \mathrm{kVA}$, respectively. The average and minimum values for the $\mathrm{OF}$ are shown in Fig. 6 and it can be concluded that the convergence of BBO algorithm is suitable for solving this problem and finding global optimum value. The figure of system's voltage profile with and without DSTATCOMs for this scenario can be seen from Fig. 7 and it shows obvious voltage profile improvement in the presence of cable aging constraint in the OF.

b) Scenario3: optimal sites and sizes of three DSTATCOMs:

In the third scenario, we use three DSTATCOMs to improve voltage profile and cable aging of the system. The average and minimum values resulted from BBO algorithm for the mentioned OF are shown in Fig. 8. As shown in this figure, the suitability of $\mathrm{BBO}$ in convergence and finding global optimum value is acceptable in this scenario. The BBO algorithm finds bus 13,14 and 17 as the optimal sites of DSTATCOMs with the size of $112.32 \mathrm{kVA}, 123.34 \mathrm{kVA}$ and $114.97 \mathrm{kVA}$, respectively. Fig. 9 demonstrates voltage profile improvement of the system with DSTATCOMs by optimally siting and sizing of DSTATCOMs in the presence cable aging constraint.

\section{Conclusion}

In this paper, voltage profile of a test system is improved considering cable aging constraint. A well-known optimization algorithm namely $\mathrm{BBO}$, is adapted to the problem of IEEE 33-bus network and optimal sites and sizes of DSTATCOMs are investigated in three different scenarios. As shown in Section $\mathrm{V}$, the suitability of $\mathrm{BBO}$ algorithm on the problem is acceptable in aspects of convergence and finding global optimum value.

\section{Appendix A}

IEEE 33-Bus test system data are given in Table A1.

Table A1

IEEE 33-Bus distribution network data

\begin{tabular}{|c|c|c|c|c|c|}
\hline \multirow[b]{2}{*}{$\begin{array}{l}\text { Sending } \\
\text { Bus }\end{array}$} & \multirow[b]{2}{*}{$\begin{array}{c}\text { Receiving } \\
\text { Bus }\end{array}$} & \multirow[b]{2}{*}{$\mathbf{R}(\Omega)$} & \multirow[b]{2}{*}{$\mathrm{X}(\boldsymbol{\Omega})$} & \multicolumn{2}{|c|}{ Receiving Bus } \\
\hline & & & & $\begin{array}{c}\mathbf{P}_{\mathbf{L}} \\
(\mathbf{k W})\end{array}$ & $\begin{array}{c}\mathbf{Q}_{\mathbf{L}} \\
(\mathbf{k V A r})\end{array}$ \\
\hline 1 & 2 & 0.0922 & 0.0477 & 100 & 60 \\
\hline 2 & 3 & 0.4930 & 0.2511 & 90 & 40 \\
\hline 3 & 4 & 0.3660 & 0.1864 & 120 & 80 \\
\hline 4 & 5 & 0.3811 & 0.1941 & 60 & 30 \\
\hline 5 & 6 & 0.8190 & 0.7070 & 60 & 20 \\
\hline 6 & 7 & 0.1872 & 0.6188 & 200 & 100 \\
\hline 7 & 8 & 1.7114 & 1.2351 & 200 & 100 \\
\hline 8 & 9 & 1.0300 & 0.7400 & 60 & 20 \\
\hline
\end{tabular}




\begin{tabular}{|c|c|c|c|c|c|}
\hline 9 & 10 & 1.0400 & 0.7400 & 60 & 20 \\
\hline 10 & 11 & 0.1966 & 0.0650 & 45 & 30 \\
\hline 11 & 12 & 0.3744 & 0.1238 & 60 & 35 \\
\hline 12 & 13 & 1.4680 & 1.1550 & 60 & 35 \\
\hline 13 & 14 & 0.5416 & 0.7129 & 120 & 80 \\
\hline 14 & 15 & 0.5910 & 0.5260 & 60 & 10 \\
\hline 15 & 16 & 0.7463 & 0.5450 & 60 & 20 \\
\hline 16 & 17 & 1.2890 & 1.7210 & 60 & 20 \\
\hline 17 & 18 & 0.7320 & 0.5740 & 90 & 40 \\
\hline 2 & 19 & 0.1640 & 0.1565 & 90 & 40 \\
\hline 19 & 20 & 1.5042 & 1.3554 & 90 & 40 \\
\hline 20 & 21 & 0.4095 & 0.4784 & 90 & 40 \\
\hline 21 & 22 & 0.7089 & 0.9373 & 90 & 40 \\
\hline 3 & 23 & 0.4512 & 0.3083 & 90 & 50 \\
\hline 23 & 24 & 0.8980 & 0.7091 & 420 & 200 \\
\hline 24 & 25 & 0.8960 & 0.7011 & 420 & 200 \\
\hline 6 & 26 & 0.2030 & 0.1034 & 60 & 25 \\
\hline 26 & 27 & 0.2842 & 0.1447 & 60 & 25 \\
\hline 27 & 28 & 1.0590 & 0.9337 & 60 & 20 \\
\hline 28 & 29 & 0.8042 & 0.7006 & 120 & 70 \\
\hline 29 & 30 & 0.5075 & 0.2585 & 200 & 600 \\
\hline 30 & 31 & 0.9744 & 0.9630 & 150 & 70 \\
\hline 31 & 32 & 0.3105 & 0.3619 & 210 & 100 \\
\hline 32 & 33 & 0.3410 & 0.5302 & 60 & 40 \\
\hline & & & & & \\
\hline
\end{tabular}

\section{REFERENCES}

[1] R.A. Hartlein, V.S. Harper, H.W. Ng, "Effects of Voltage Impulses on Solid Dielectric Cable Life", Power Engineering Review, IEEE, vol. 9, pp. 39-40, 1989.

[2] Lyle, R.; "Effect of testing parameters on the outcome of the accelerated cable life test", Power Delivery, IEEE Transactions on, vol. 3, pp. 434439, 1988.

[3] Seyed-Alireza Ahmadi, H. Karami, M. J. Sanjari, B. Zaker and G. B. Gharehpetian, "Cable Aging and Loadability Consideration in HSABased DG Placement", 7th Iranian Conference on Electrical Electronics and Engineering (ICEEE 2015), Gonabad, Iran, Aug. 19-20, 2015.

[4] H. Karami, Seyed-Alireza Ahmadi, M. J. Sanjari, B. Zaker and G. B. Gharehpetian, "Optimal DSTATCOM Placement by Considering Cable Aging Constraint and Voltage Profile Improvement", 7th Iranian Conference on Electrical Electronics and Engineering (ICEEE 2015), Gonabad, Iran, Aug. 19-20, 2015

[5] H. Karami, M.J. Sanjari, A. Tavakoli, G.B. Gharehpetian, "HSA-Based Optimal Allocation of DGs Considering Cable Aging Constraint", 2nd International Conferences on Renewable Energy and Distributited Generated (ICREDG), Tehran, Iran, 06-08 March, 2012.

[6] H. Karami, M.J. Sanjari, A. Tavakoli, G.B. Gharehpetian, M.S.A. Hejazi, "HSA-Based Optimal Allocation and Sizing of Shunt Compensators Considering Cable Aging Constraint and Load Variations", International Conference on Renewable Energies and Power Quality, Cordoba (Spain), 8th to 10th April, 2014.

[7] H. Karami, M.J. Sanjari, S.H. Hosseinian, G.B. Gharehpetian, "An Optimal Dispatch Algorithm for Managing Residential Distributed Energy Resources", IEEE Transaction on Smart Grid, Vol., Issue: 5, pp. 2360-2367, 2014.

[8] H. Karami, M. J. Sanjari, G. B. Gharehpetian, "Hyper-Spherical Search (HSS) Algorithm: A Novel Meta-heuristic Algorithm to Optimize Nonlinear Functions", Neural Computing and Applications, Vol. 25, issue: 6, pp. 1455-1465, 2014.

[9] A. Tavakoli, M.J. Sanjari, H. Karami, S.H. Hosseinian, G.B. Gharehpetian, "ICA-Based Unit Commitment Considering Risk of Cascading Blackout", has been accepted in Electric Power Components and Systems, DOI: 10.1080/15325008.2014.963261.

[10] H. Karami, M. J. Sanjari, Sajjad Hadavi, S. H. Hosseinian, G. B. Gharehpetian, "Stochastic Load Effect on Home Energy System
Scheduling Optimization", has been accepted in European Transaction on Electrical Power. DOI: 10.1002/etep.1970.

[11] H. Karami, M. J. Sanjari, A. Tavakoli and G. B. Gharehpetian, "Optimal Scheduling of Residential Energy System Including CHP System and Storage Device", Electric Power Components and Systems, Volume 41, Issue 8, April 2013, pages 765-780.

[12] M.J. Sanjaria, H. Karami, A.H. Yatim, G.B. Gharehpetian, "Application of Hyper-Spherical Search algorithm for optimal energyresources dispatch in residential microgrids", Applied Soft Computing, Vol. 37, pp. 15-23, 2015.

[13] Dan Simon. "Biogeography-based optimization." IEEE Transactions on Evolutionary Computation, Vol. 12, Issue 6, pp. 702-713, 2008.

[14] MJ Sanjari, AJ Ghanizadeh, GB Gharehpetian, "Dual functional series compensator to reduce fault current in a distribution system with DG units", International Journal of Engineering, Science and Technology, Vol. 3, No.11, pp.15-27, 2011.

[15] M. J. Sanjari, S. H. Fathi, G. B. Gharehpetian and A. Tavakoli, "HSABased Optimal Placement of Shunt FACTS Devices in the Smart Grid Considering Voltage Stability", 2nd Iranian Conference on Smart Grids, ICSG 2012, Tehran, Iran, May 23-24, 2012.

[16] Blazic B, Papic I. A new mathematical model and control of DSTATCOM for operation under unbalanced conditions. Electr Power Syst Res 2004;72(3):279-287.

[17] Seyed Abbas Taher, Seyed Ahmadreza Afsari, "Optimal location and sizing of DSTATCOM in distribution systems by immune algorithm", Electrical Power and Energy Systems, Vol. 60, pp. 34-44, 2014.

[18] Majumder, R., "Reactive Power Compensation in Single-Phase Operation of Microgrid", Industrial Electronics, IEEE Transactions on, Volume 60 , Issue: 4, pp. 1403-1416, 2013.

[19] Giroux, P., Sybille, G., Hoang Le-Huy, "Modeling and simulation of a distribution STATCOM using Simulink's Power System Blockset", Industrial Electronics Society, 2001. IECON '01. The 27th Annual Conference of the IEEE, pp. 990 - 994 vol.2, 2001.

[20] Ghosh S, Das D. Method for load-flow solution of radial distribution networks. IEE ProcGenerTransmDistrib 1999;146(6):641-8. 